\title{
Understanding of Pathophysiological Basis of Feeding Intolerance in Critically ill Children
}

\author{
(D) Soyhan Bağcı ${ }^{1}$, (D) Elif Keleş Gülnerman², (D) Andreas Mueller ${ }^{1}$ \\ ${ }^{1}$ Bonn University Children's Hospital, Department of Neonatology and Pediatric Intensive Care, Bonn, Germany \\ ${ }^{2}$ Gazi University Faculty of Medicine, Department of Neonatology, Ankara, Turkey
}

\section{ABSTRACT}

Children with critical illnesses are at increased risk for intestinal injury, gastrointestinal dysfunction, and feeding intolerance, which are associated with delayed recovery and increased morbidity and mortality during their course in the pediatric intensive care unit (PICU). Optimizing energy and protein delivery significantly reduces the incidence of infectious complications and multiorgan failure in critical illness. Enteral nutrition (EN) is the preferred mode of nutrient intake in patients with critical illnesses. Despite the growing awareness of the benefits of EN in patients with critical illnesses, subsequent maintenance of EN delivery in PICUs remains suboptimal. In children with critical illnesses, little data are reported on the factors that influenced EN. Feeding intolerance in children with critical illnesses may be due to alterations in gastrointestinal motility secondary to underlying disease or medication administration. This study aimed to summarize recent insights into the role of hyperglycemia, EN caloric density, and gastrointestinal feedback mechanism, and routine intensive care management, such as sedation, analgesia, and catecholamine on feeding intolerance in children with critical illnesses.

Keywords: Feeding intolerance, gastric emptying, opioid, catecholamine, children

\section{Introduction}

Children with a critical illness are at increased risk for intestinal injury, gastrointestinal dysfunction, and feeding intolerance, which are associated with delayed recovery and increased morbidity and mortality during their course in the pediatric intensive care unit (PICU). Moreover, malnutrition is a frequent finding in children with a critical illness $(1,2)$. The prevalence of severe malnutrition in PICU admission of children with a critical illness is reported to be over $30 \%$, as it was 30 years ago $(1,2)$.
Optimizing energy and protein delivery significantly reduces the incidence of infectious complications and multiorgan failure in critical illness $(3,4,5)$. Therefore, the provision of optimal nutritional therapy is a fundamental goal of critical care.

Enteral nutrition (EN) is the preferred mode of nutrient intake in patients with critical illness with a functional gastrointestinal system because studies have shown multiple beneficial effects of EN compared with parenteral nutrition (PN). EN allows the use of the nutrients better than PN, and maintains gastrointestinal integrity, and

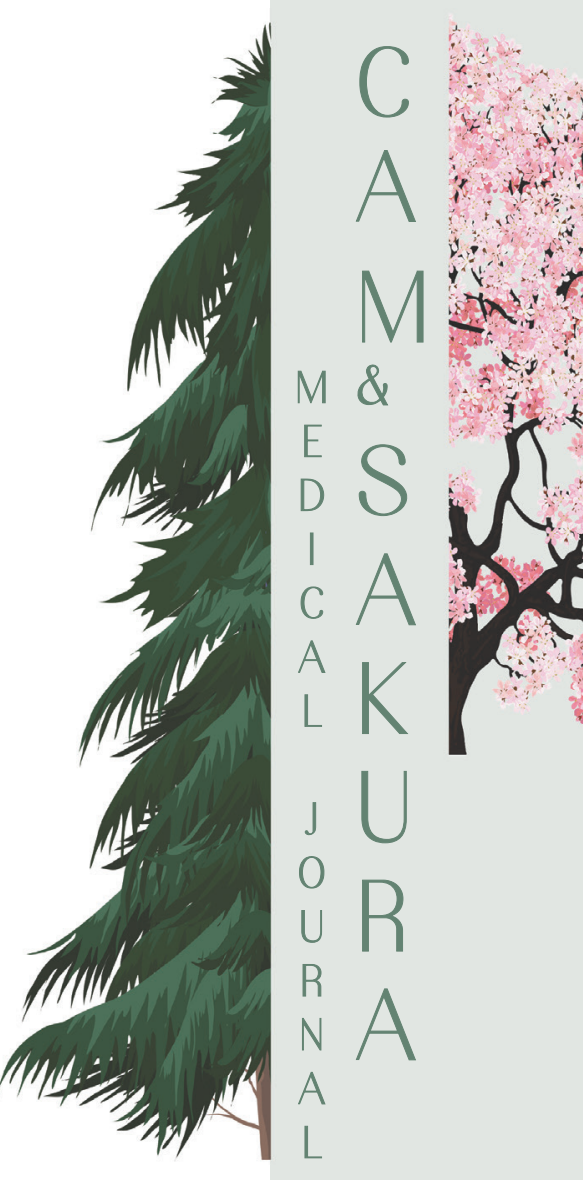

Address for Correspondence: Soyhan Bağcı Prof. MD, Bonn University Children's Hospital, Department of Neonatology and Pediatric Intensive Care, Bonn, Germany

Phone: +49-228-287-37837 E-mail: soyhan.bagci@ukbonn.de ORCID ID: orcid.org/0000-0003-1005-665X Received: 03.04.2021 Accepted: 17.05.2021

(C) Copyright 2021 by the Cam \& Sakura Medical Journal published by Galenos Publishing House. 
improves gastrointestinal barrier dysfunction by its trophic effect, stimulates the immune system, and reduces intestinal bacterial translocation $(3,4,5)$. The Society of Critical Care Medicine and the American Society for Parenteral and Enteral Nutrition promoted early EN of patients in the PICU (6).

Despite the growing awareness of the benefits of EN in patients with critical illness, subsequent maintenance of EN delivery in PICUs remains suboptimal (2). On average, nearly $50 \%$ of children with critical illness in most reports fail to reach nutrition goals, with $37-70 \%$ of prescribed energy delivery before discharge from the PICU $(7,8)$. EN is frequently impeded or interrupted in the PICU for a variety of reasons, failing to achieve nutrition goals $(2,7)$. An important factor contributing to inadequate provision of EN is feeding intolerance, which occurs frequently due to delayed gastric emptying and gut dysmotility in critical illness. The reported prevalence of feeding intolerance in a recent systematic review ranged from $0.0 \%$ to $57.1 \%$ with a median prevalence of $20.0 \%$ (Interquartile range $7.4-33.0$ ) (9). This wide range is due to the confusion in feeding intolerance definition, which often results in unnecessary feeding interruptions in children with a critical illness $(9,10)$.

Generally, feeding intolerance means the presence of high gastric residual volume, vomiting, diarrhea, and abdominal distention $(9,10)$. However, compared to adults, signs of feeding intolerance in children are difficult to quantify and can be easily confused with gastrointestinal symptoms associated with a patient's medications or underlying illness.

In children with critical illness, little data is reported on the factors that influenced EN. Feeding intolerance in children with critical illness may be due to alterations in gastrointestinal motility secondary to the underlying disease or medication administration. This study aimed to summarize recent insights into the role of hyperglycemia, the caloric density of EN, and gastrointestinal feedback mechanism, and routine intensive care management, such as sedation, analgesia, and catecholamine, on the feeding intolerance in children with a critical illness.

\section{Pathophysiological Basis of Feeding Intolerance}

\section{Control of Gastric Emptying}

The main function of the stomach is to act as a reservoir of ingested food and perform a mechanical and chemical breakdown of the contents to a fluid chyme that is delivered to the duodenum at a controlled rate. The regulation of gastric emptying is a complex process, which allows optimal intestinal digestion and absorption of foodstuffs. The rate of gastric emptying is determined by the integrated activity of the proximal stomach, antrum, pylorus, and proximal small intestine (11).

The proximal fundus of the stomach functions as a reservoir, and the muscles are adapted to maintain a continuous contractile tone, whereas the antro pyloro duodenal region exhibits phasic and peristaltic contractile activity and functions both as a pump and a grinding mill. The pyloric sphincter tone regulates the outflow to the small intestine. The interaction of nutrients with the small intestine plays a major role in gastric emptying regulation; small-intestinal nutrients slow gastric emptying, which is associated with proximal stomach relaxation, antral contraction suppression, and pyloric motility stimulation (12). Moreover, other factors, including the systemic hormonal environment, enteric nerve activity, central nervous system drive, and ingested meal properties, appear to regulate gastric emptying. Consequently, changes in any of these factors will affect the rate of gastric emptying (13).

\section{Delayed Gastric Emptying in Critical Illness}

In patients with critical illness, a marked reduction in antral motility and poor coordination of antroduodenal contractions has been reported during fasting. In addition, proximal and distal gastric motor responses to small-intestinal nutrient stimulation are abnormal in critical illnesses. Moreover, proximal gastric relaxation and the recovery of proximal gastric volumes to pre-stimulation levels are delayed and fundic wave activity and antral motility are reduced $(14,15)$. Failure of the relaxed proximal stomach to return to baseline volume after nutrient stimulation in these patients provides a reservoir for gastric residue retention in the fundus.

\section{Factors Contributing to Gastric Emptying Delay in Children with Critical Illness}

The pathophysiology of delayed gastric emptying in children with critical illness is multifactorial. Delayed gastric emptying was reported to be due to impaired gastroduodenal motility related to patients' clinical severity, premorbid conditions, and pharmacological and surgical treatments. Only a few studies specifically focus on delayed gastric emptying in children with critical illnesses. Thus, this study reviewed the outstanding animal and observational adult studies that clarify the factors that contribute to a gastric emptying delay in children with critical illnesses.

\section{Food Composition Effects}

In healthy subjects, a relaxed proximal stomach, reduced antro-duodenal motility, and increased isolated pyloric 
pressure waves were found in response to small-intestinal feedback (12). Lin et al. (16) demonstrated that the proximal, as well as the distal small intestine, are capable of participating in negative feedback control.

Gastric emptying appears to be regulated by factors, such as the systemic hormonal environment, enteric nerve activities, central nervous system drive, and ingested meal properties. The relative importance of these factors has not been exactly established; however, some evidence presented that the rate of emptying of both solids and liquids depends on their chemical compositions. Several studies have identified different meal properties, which influence the rate of gastric emptying. Low $\mathrm{pH}$ and temperature, as well as high osmolality, viscosity, fiber content, and caloric density, delay gastric emptying $(17,18)$. However, Calbet and MacLean (19) reported that the rate of gastric emptying is mainly a function of the caloric density of the ingested meal and that a linear relationship exists between these variables when solutions of similar volumes and osmolalities are administered at the same temperature and $\mathrm{pH}$ in healthy humans. For example, an increasing caloric density of 6-fold resulted in a 3-fold decreased rate of gastric emptying (19). Moreover, the rates of gastric emptying for isocaloric amounts of fat, protein, and carbohydrates were reported to be similar, suggesting that the delaying effect of caloric density on gastric emptying seems to be independent of the nature of the solutes $(20,21)$. In addition, the energy properties of the meal are detected by duodenal receptors, which regulate the rate of gastric emptying (17).

Caloric content plays a crucial role in gastric emptying; however, differences in solution osmolality may also change the rate of gastric emptying. A hyperosmolar solution is thought to slow gastric emptying by triggering duodenal osmoreceptor feedback on the stomach $(22,23)$, which may be especially important in patients who receive post-pyloric feeding. Nevertheless, the influence of osmolality on the rate of gastric emptying may be of physiological relevance only at high tonicity levels (1,200 mosmol/ $\left./ \mathrm{kg} \mathrm{H}_{2} \mathrm{O}\right)(23)$.

\section{Enterogastric Feedback Hormones Effects}

Cholecystokinin (CCK) and peptide YY (PYY) are important enterogastric feedback hormones, which regulate gastric emptying. In response to the presence of fat and protein in the small intestine, CCK and PYY are released in a dosedependent fashion from the enteroendocrine cells, which are predominantly located in the proximal small intestine for CCK and the distal small intestine for PYY $(24,25)$. The initial release of PYY after food intake is likely to be mediated by
CCK (26). Endogenous CCK has been demonstrated as an important regulator of gastric emptying of both the solid and liquid meal phases and thus a major determinant of gastric emptying of a physiological meal in humans (27). An exogenous administration of CCK and PYY is associated with proximal stomach relaxation, antral motor activity inhibition, isolated pyloric contraction stimulation, and gastric emptying slowing $(27,28)$.

Proximal and distal gastric motor responses to smallintestinal nutrient stimulation are demonstrated to be abnormal in critical illness. In addition, proximal gastric relaxation and proximal gastric volumes recovery to prestimulation levels are delayed and fundic wave activity and antral motility are reduced (14). Failure of the relaxed proximal stomach to return to baseline volume after nutrient stimulation in these patients provides a reservoir for gastric residue retention in the fundus. Nguyen et al. $(29,30)$ demonstrated in their studies that both fasting and nutrient-stimulated plasma CCK and PYY concentrations are increased in patients with critical illnesses, particularly in those with feeding intolerance, suggesting a contribution of this hormone in delayed gastric emptying. Moreover, a close relationship has been reported between nutrient-stimulated plasma PYY and CCK concentrations in these patients (29). As gastric emptying was inversely related to postprandial plasma CCK and PYY concentrations in patients with critical illnesses, these studies suggested that hypersensitivity to a smallintestinal nutrient leads to motility changes, which result in reduced gastric emptying, is found in critical illness $(29,30)$.

\section{Blood Glucose Concentration Effects}

Changes in blood glucose concentration are among the most frequently encountered components of disturbed homeostasis in children with critical illnesses. Hyperglycemia is a risk factor for poor outcomes in patients with critical illness, and tight glycemic control improves clinical outcomes, including survival (31). Mechanical ventilation, vasopressor/ inotropic infusion, continuous renal replacement therapy, and high illness severity scores were known to be associated with hyperglycemia in these patients (32). No definite criteria for hyperglycemia diagnosis among patients without diabetes mellitus, thus the authors used more than two cut-off values to present the hyperglycemic status of children with critical illness in their studies. Through the use of cut-off values of blood glucose level $>110 \mathrm{mg} / \mathrm{dL}, 120$ or $126 \mathrm{mg} / \mathrm{dL}, 150 \mathrm{mg} /$ $\mathrm{dL}$, and $200 \mathrm{mg} / \mathrm{dL}$, the reported incidence of hyperglycemia in children with critical illness ranged from $85 \%$ to $95 \%$, 70 $86 \%, 61-72 \%$, and $16.7-35.2 \%$, respectively $(33,34,35)$. 
Acute changes in the blood glucose concentration were well recognized to have a major reversible effect on gastrointestinal motility and rate of gastric emptying in both healthy participants and those with diabetes. Acute hyperglycemia that is induced by intravenous glucose infusion was shown to slow the emptying of nutrient-containing liquid and solid meals in patients with and those without diabetes (36), whereas hypoglycemia has the opposite effect and increases the gastric emptying rate for both liquid and solid meals in healthy volunteers and patients with insulindependent diabetes mellitus (37). In healthy volunteers and patients with type 1 diabetes, hyperglycemia stimulates phasic pressure waves that are localized to the pylorus, reduces the frequency and propagation of antral pressure waves under fasting and postprandial conditions, and increases proximal gastric compliance, which reflects a gastric tone reduction $(38,39)$. Furthermore, marked hyperglycemia (blood glucose 210-270 mg/dL) showed to decrease in the motility index and propagation of duodenal and jejunal waves and slow smallintestinal transit in healthy volunteers $(38,40)$.

Recent observations indicate that not only pathological but also physiological changes in the blood glucose concentration within the normal postprandial range (140$180 \mathrm{mg} / \mathrm{dL}$ ) act synergistically with stimuli that arise from the small intestine to slow gastric emptying of solid and liquid meals. For example, at a blood glucose concentration of 180 $\mathrm{mg} / \mathrm{dL}$ (10 mmol/L), the phasic and tonic pyloric responses to duodenal distension are greater than during euglycemia (41). Antral motility index was noted to be significantly reduced when intravenous glucose infusions raised serum glucose levels to approximately $120 \mathrm{mg} / \mathrm{dL}(6.6 \mathrm{mmol} / \mathrm{L})$ in fasting humans (42). Moreover, the stimulation of pyloric tone by exogenous CCK was demonstrated to be greater and gastric emptying is slower at a blood glucose level of $144 \mathrm{mg} / \mathrm{dL}(8$ $\mathrm{mmol} / \mathrm{L}$ ) compared with $72 \mathrm{mg} / \mathrm{dL}(4 \mathrm{mmol} / \mathrm{L})$ in both healthy participants and patients with diabetes $(43,44)$. Furthermore, the evidence presented that hyperglycemia attenuates the prokinetic effect of intravenous erythromycin on gastric emptying in both healthy participants and patients with diabetes (45).

Contrarily, patients with type 1 diabetes without complications had markedly accelerated gastric emptying during hypoglycemia compared with euglycemia, as in healthy participants (37). The finding that cholinergic muscarinic blockade with atropine inhibited the hypoglycemia-induced acceleration of gastric emptying indicates that vagal stimulation plays an important role in this mechanism $(46,47)$.

\section{Sedation and Analgesic Effects}

Many sedative and analgesic agents that are commonly administered in the PICU are known to have negative effects on the digestive system with gastric emptying inhibition and small-bowel transit prolongation $(48,49,50)$.

Propulsive gut motility inhibition is especially marked after an opioid-based technique. The inhibitory effect of opioids on gastrointestinal motility has been extensively studied, but the mechanism and understanding are complex. Opioid receptors are known to be present in the gastrointestinal tract. Gut motility inhibition is mainly mediated via opioid receptors because recently developed opioid antagonists reverse opioidinduced gastrointestinal motility inhibition $(51,52)$. Another effect of opioid analgesics is the inhibition of the release of acetylcholine from the mesenteric plexus, thereby increasing colonic muscle tone and reducing propulsive activity in the gastrointestinal tract $(53,54)$. Moreover, the pylorus has been clearly shown to have rich enkephalinergic innervation, and opioids may therefore increase pyloric tone (55).

Morphine, even at a low dose, markedly inhibits gastric emptying due to enhanced proximal gastric relaxation, increased pyloric tone, and increased retrograde duodenal contractions in healthy humans $(48,49,50)$. Remifentanil, an ultra-short-acting opioid, increases pyloric tone and thereby delays gastric emptying (56). Using a guinea-pig small-bowel model, Fruhwald et al. (57) demonstrated that sufentanil, an ultra-short-acting opioid and $\mu$-receptor agonist, had a very strong inhibitory effect on small-bowel motility at moderate concentrations. The most striking finding of this study was that the antiperistaltic effect of epinephrine on intestinal motility is intensified by the combination of sufentanil, especially if the opioid is given at moderate and higher concentrations. Contrary to epinephrine, dobutamine seems to be less capable of depressing peristalsis even when combined with higher sufentanil concentrations (57). Therefore, the physician in the ICU should be alert to possible negative interactions during the long-term combination of opioids and catecholamines, such as epinephrine, norepinephrine, dopamine, and vasopressin combinations, in patients with critical illnesses.

In a laboratory setting, propofol exhibits an inhibitory effect on spontaneous contractile activity and concentrationdependent depression of acetylcholine-induced contraction on human gastric and colonic smooth muscles at clinically relevant concentrations (58). Clinical studies involving human volunteers who are lightly sedated with propofol demonstrated a significantly increased orocecal transit time 
$(59,60)$. Contrarily, propofol at low doses (up to $5 \mathrm{mg} / \mathrm{kg} / \mathrm{h}$ over 1-3 h) has been reported to not affect gastric emptying in healthy humans or in patients who have undergone minor surgery $(60,61)$. In addition, Nguyen et al. (62) recently demonstrated that $56 \%$ of patients with critical illness who are sedated with propofol in their study at a mean rate of $\sim 2 \mathrm{mg} /$ $\mathrm{kg} / \mathrm{h}$ had delayed gastric emptying. However, the incidence of delayed gastric emptying in patients who received propofol was significantly lower than in patients who are sedated with morphine and midazolam. Moreover, whether the delayed gastric emptying is an effect of propofol or critical illness remains unclear (62). An animal study reported that midazolam slows gastric emptying in mice (63). The inhibitory effects of morphine and midazolam on gastric motility are also observed in patients with critical illnesses $(64,65)$.

Ketamine is a unique drug because it is a powerful analgesic in addition to its dissociative anesthetic property. Ketamine was previously demonstrated to suppress endotoxininduced production of proinflammatory cytokines, such as tumor necrosis factor-alpha and interleukin-6 production in the intestine $(66,67)$. Recently, Suliburk and Mercer (68) demonstrated that ketamine attenuates lipopolysaccharides that induced increases in gastric volume and gastric $\mathrm{pH}$ in rats.

Clonidine and dexmedetomidine are potent and selective a2-adrenoceptor agonists with sedative and analgesic properties, which are used for perioperative and intensive care sedation. Moreover, clonidine and dexmedetomidine have been reported to facilitate some signs and symptoms of opioid and benzodiazepine withdrawal. Therefore, they are preferred as a non-opioid alternative for managing opiate withdrawal syndrome, not only in adults but also in infants and children with a critical illness $(69,70,71)$. The physiological role of $\alpha 2$-adrenoceptors in the regulation of gastrointestinal function has been documented (72,73). Activation of $\alpha 2$-adrenoceptors has been reported to mediate several responses in the gastrointestinal tract $(72,73)$. Clonidine and dexmedetomidine were shown to inhibit gastric acid secretion, gastric emptying, and gastrointestinal transit in animal and human studies $(73,74,75)$. Recently, lirola et al. (76) demonstrated that dexmedetomidine markedly inhibited gastric emptying and orocecal transit compared with placebo and morphine in healthy volunteers.

In conclusion, patients who are sedated with opioids and midazolam are more likely to have slow gastric emptying, and proximal meal retention and may be at higher risk of feeding intolerance, gastroesophageal reflux, and aspiration pneumonia than those receiving propofol or ketamine. Ketamine may be preferred as the analgesic drug of choice, combined with propofol rather than a high-dose barbiturate, midazolam, or opioids in patients with critical illness, especially with sepsis or septic shock.

\section{Catecholamine Effects}

In the 1970s, catecholamines, which are frequently used in patients with critical illness because of their cardiovascular effects, were described to significantly alter the rate of gastric emptying (77). The role of alfa- and beta-adrenoceptors and dopamine receptors in the regulation of gastrointestinal motility were well documented $(78,79,80)$. Catecholamines can affect gastric and intestinal motility through direct activation of smooth muscle adrenoceptors, which may belong to the alfa-1, alfa-2, beta-1, beta-2, and beta-3-class $(74,81,82)$. In general, both alfa- and beta-adrenoceptor agonists inhibit gastric or intestinal motility in experimental animals by a direct effect on the smooth muscle or by neural inhibition (83). However, the inhibitory effect of catecholamines on gastric emptying and intestinal motility are dominantly due to the activation of alfa- 2 and dopamine- 2 receptors. The alpha receptors are found not only in the smooth muscle, such as beta-adrenoceptors, but also on the nerves that modify the release of neurotransmitters, such as acetylcholine, which is an excitatory neurotransmitter in the intestine, and its release increases smooth muscle contraction. The inhibition of acetylcholine release is mediated by alpha-adrenoceptors. Moreover, the activation of DA-2 neural receptors appears to depress digestive motility via an inhibition of acetylcholine that is a release from cholinergic motor neurons that innervate gastrointestinal smooth muscle (84).

Dopamine receptors (DA-2) are known to be present in the human enteric nervous system (85). In mechanically ventilated patients with critical illness, Dive et al. (86) demonstrated that continuous intravenous administration of dopamine at a low dose (4 $\mu \mathrm{g} / \mathrm{kg}$ per min) decreased the number of contractions in the gastric antrum and induced phase III motor activity in the duodenum both during fasting and during continuous nasogastric feeding. Similar results were observed by Levein et al. (87) in healthy male participants. They reported that a continuous infusion of dopamine at 5 micrograms $\mathrm{kg}^{-1} \mathrm{~min}^{-1}$ slows gastric emptying and prolongs orocecal transit time (87). In addition to its depressing effect on the antrum, Hartley et al. (88) have shown that dopamine that is infused at a rate of 2 $\mu \mathrm{g} / \mathrm{kg}$ per min is normally used to promote renal function and produced a profound relaxation of the corpus fundus of the stomach in healthy volunteers. The authors concluded that giving dopamine at that dose to patients who are receiving nasogastric feeding may put them at risk of vomiting, regurgitation, and gastric content aspiration. 
Recently, an experimental study of pharmacologic effects of catecholamines on intestinal motility demonstrated that catecholamines markedly differ in their inhibitory and stimulatory actions on the peristaltic motility of guinea-pig ileum (79). Dobutamine and dopexamine are $\sim 500$ times less potent in inhibiting peristalsis than epinephrine, which shows the most inhibitory potency among the catecholamines (79). The authors concluded that the low inhibitory potency of dobutamine (beta 1-adrenoceptor agonist) and dopexamine (beta 2-adrenoceptor agonist and dopamine receptor agonist) are consistent with the finding that alpha-adrenoceptor agonists are more active in inhibiting acetylcholine release from the enteric neurons and suppressing peristalsis than beta-adrenoceptor agonists $(79,81)$. The $\alpha 2$-adrenoceptor agonists clonidine and dexmedetomidine are used as additive analgesic drugs that inhibit gastric, small bowel, and colonic motility in animal and human studies $(74,75,78)$.

Fruhwald et al. (79) ranked inhibitory potency of catecholamines on the peristaltic motility of guinea-pig ileum in vitro as follows: Epinephrine $>$ norepinephrine $>$ dopamine $>$ dobutamine $\sim$ dopexamine (Table 1 summarizes the effects of different catecholamines on different receptors). The use of dobutamine and dopexamine may be preferred in patients with critical illness because of their low potency in suppressing intestinal propulsion, but this recommendation is only based on their effects on intestinal motility and does not take their effects on gut perfusion into account (79). Inadequate splanchnic perfusion in the critically ill is known to compromise the gut barrier that leads to bacterial translocation, which may ultimately lead to multiple organ dysfunction. The evidence demonstrates that dopexamine, dobutamine, and dopamine increase splanchnic perfusion, thereby protecting the gut from further injury.

The effect of vasopressin on the $\mathrm{Gl}$ tract is only rudimentary examined. Using a dog model, Xu et al. (89) showed that that vasopressin significantly delayed gastric emptying and induced gastric and intestinal dysrhythmia. Compared with the gastric slow wave, the inhibitory effect of vasopressin on the intestinal slow wave was relatively mild. Similar results were reported by Langhans et al. (90) in rats, which demonstrated that intraperitoneally injected vasopressin inhibits gastric emptying and reduces food intake in rats. This effect was mediated by an alpha-adrenergic mechanism (91).

Caras et al. (92) studied the effects of vasopressin on gastric myoelectrical activity in healthy women. They demonstrated that intravenous vasopressin influences gastric motility and result in gastric arrhythmia, predominantly bradyarrhythmias, and caused significant nausea and abdominal cramping compared with baseline and controls in dose-dependent fashions (92).

In conclusion, several studies support that the use of dobutamine and dopexamine in critical illness may be more protective on the gastrointestinal system than other catecholamines, including preservation of gut mucosal integrity and lower risk of delayed gastric emptying.

\section{CONCLUSION}

Causes for feeding intolerance remain unclear and are probably multifactorial during critical illness. A better understanding of its pathophysiology in children with critical illness may allow an optimized strategy to avoid motility disorders. Therapeutic options, however, are still limited. Current recommendations mostly focused on optimizing all factors that contribute to delayed gastric emptying, early initiation of EN, and individual use of prokinetic agents. Insufficient studies preclude the routine use of newer therapeutic approaches, such as $\mu$-opioid and CCK receptor agonists in children with critical illness and the further investigation appears warranted based on their risk/benefit ratios.

Table 1. Effects of different catecholamines on different receptors

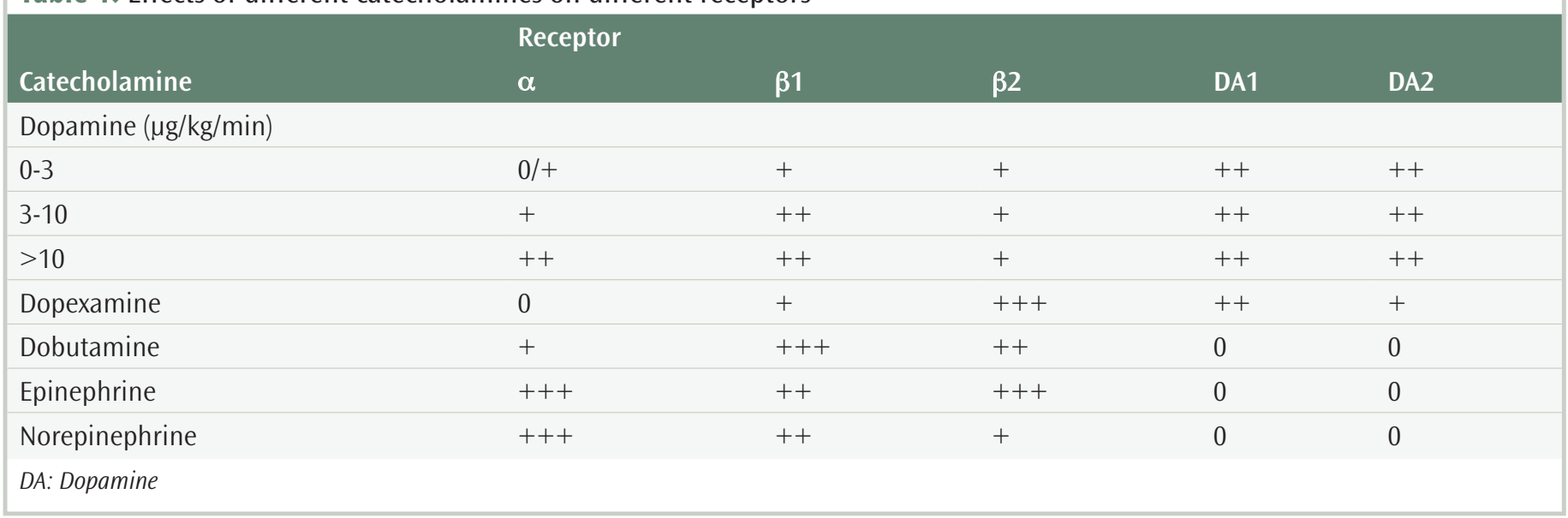




\section{Ethics}

Peer-review: Internally peer-reviewed.

\section{Authorship Contributions}

Concept: S.B., A.M., Design: S.B., A.M., Literature Search: S.B., E.K.G., Writing: S.B., E.K.G.
Conflict of Interest: No conflict of interest was declared by the authors.

Financial Disclosure: The authors declared that this study received no financial support.

\section{REFERENCES}

1. Pollack MM, Wiley JS, Holbrook PR. Early nutritional depletion in critically ill children. Crit Care Med 1981;9:580-583.

2. Mehta NM, Bechard LJ, Cahill N, et al. Nutritional practices and their relationship to clinical outcomes in critically ill children-an international multicenter cohort study*. Crit Care Med 2012;40:2204-2211.

3. Mehta NM, McAleer D, Hamilton S, et al. Challenges to optimal enteral nutrition in a multidisciplinary pediatric intensive care unit. JPEN J Parenter Enteral Nutr 2010;34:38-45.

4. de Lucas C, Moreno M, López-Herce J, Ruiz F, Pérez-Palencia M, Carrillo A. Transpyloric enteral nutrition reduces the complication rate and cost in the critically ill child. J Pediatr Gastroenterol Nutr 2000;30:175-180.

5. Rey C, Alvarez F, De-La-Rua V, et al. Intervention to reduce catheterrelated bloodstream infections in a pediatric intensive care unit. Intensive Care Med 2011;37:678-685.

6. Mehta NM, Compher C; A.S.P.E.N. Board of Directors. A.S.P.E.N. Clinical Guidelines: nutrition support of the critically ill child. JPEN J Parenter Enteral Nutr 2009;33:260-276.

7. Rogers EJ, Gilbertson HR, Heine RG, Henning R. Barriers to adequate nutrition in critically ill children. Nutrition 2003;19:865-868.

8. Taylor RM, Preedy VR, Baker AJ, Grimble G. Nutritional support in critically ill children. Clin Nutr 2003;22:365-369.

9. Eveleens RD, Joosten KFM, de Koning BAE, Hulst JM, Verbruggen SCAT. Definitions, predictors and outcomes of feeding intolerance in critically ill children: a systematic review. Clin Nutr 2020;39:685693.

10. Reintam Blaser A, Starkopf L, Deane AM, Poeze M, Starkopf J. Comparison of different definitions of feeding intolerance: a retrospective observational study. Clin Nutr 2015;34:956-961.

11. Horowitz M, Dent J. Disordered gastric emptying: mechanical basis, assessment and treatment. Baillieres Clin Gastroenterol 1991;5:371407.

12. Heddle R, Collins PJ, Dent J, et al. Motor mechanisms associated with slowing of the gastric emptying of a solid meal by an intraduodenal lipid infusion. J Gastroenterol Hepatol 1989;4:437-447.

13. Hellström PM, Grybäck P, Jacobsson H. The physiology of gastric emptying. Best Pract Res Clin Anaesthesiol 2006;20:397-407.

14. Chapman M, Fraser R, Vozzo R, et al. Antro-pyloro-duodenal motor responses to gastric and duodenal nutrient in critically ill patients. Gut 2005;54:1384-1390.
15. Nguyen NQ, Fraser RJ, Chapman M, et al. Proximal gastric response to small intestinal nutrients is abnormal in mechanically ventilated critically ill patients. World J Gastroenterol 2006;12:4383-4388.

16. Lin HC, Doty JE, Reedy TJ, Meyer JH. Inhibition of gastric emptying by glucose depends on length of intestine exposed to nutrient. Am J Physiol 1989;256(2 Pt 1):G404-411.

17. Brener W, Hendrix TR, McHugh PR. Regulation of the gastric emptying of glucose. Gastroenterology 1983;85:76-82.

18. Lin HC, Doty JE, Reedy TJ, Meyer JH. Inhibition of gastric emptying by acids depends on $\mathrm{pH}$, titratable acidity, and length of intestine exposed to acid. Am J Physiol 1990;259(6 Pt 1):G1025-1030.

19. Calbet JA, MacLean DA. Role of caloric content on gastric emptying in humans. J Physiol 1997;498 (Pt 2)(Pt 2):553-559.

20. Hunt JN, Smith JL, Jiang CL. Effect of meal volume and energy density on the gastric emptying of carbohydrates. Gastroenterology 1985;89:1326-1330.

21. Maerz LL, Sankaran H, Scharpf SJ, Deveney CW. Effect of caloric content and composition of a liquid meal on gastric emptying in the rat. Am J Physiol 1994;267(5 Pt 2):R1163-1167.

22. Meeroff JC, Go VL, Phillips SF. Control of gastric emptying by osmolality of duodenal contents in man. Gastroenterology 1975;68(5 Pt 1):1144-1151.

23. Lin HC, Elashoff JD, Gu YG, Meyer JH. Nutrient feedback inhibition of gastric emptying plays a larger role than osmotically dependent duodenal resistance. Am J Physiol 1993;265(4 Pt 1):G672-676.

24. Adrian TE, Ferri GL, Bacarese-Hamilton AJ, Fuessl HS, Polak JM, Bloom SR. Human distribution and release of a putative new gut hormone, peptide YY. Gastroenterology 1985;89:1070-1077.

25. Liddle RA, Morita ET, Conrad CK, Williams JA. Regulation of gastric emptying in humans by cholecystokinin. J Clin Invest 1986;77:992996

26. Lin HC, Chey WY, Zhao XT. Release of distal gut peptide YY (PYY) by fat in proximal gut depends on CCK. Peptides 2000;21:1561-1563.

27. Borovicka J, Kreiss C, Asal K, et al. Role of cholecystokinin as a regulator of solid and liquid gastric emptying in humans. Am J Physiol 1996;271(3 Pt 1):G448-453.

28. MacIntosh CG, Andrews JM, Jones KL, et al. Effects of age on concentrations of plasma cholecystokinin, glucagon-like peptide 1 , and peptide $\mathrm{YY}$ and their relation to appetite and pyloric motility. Am J Clin Nutr 1999;69:999-1006. 
29. Nguyen NQ, Fraser RJ, Chapman M, et al. Fasting and nutrientstimulated plasma peptide-YY levels are elevated in critical illness and associated with feed intolerance: an observational, controlled study. Crit Care 2006;10:R175.

30. Nguyen NQ, Fraser RJ, Bryant LK, et al. The relationship between gastric emptying, plasma cholecystokinin, and peptide $Y Y$ in critically ill patients. Crit Care 2007;11:R132.

31. Preissig CM, Hansen I, Roerig PL, Rigby MR. A protocolized approach to identify and manage hyperglycemia in a pediatric critical care unit. Pediatr Crit Care Med 2008;9:581-588.

32. Preissig CM, Rigby MR. Pediatric critical illness hyperglycemia: risk factors associated with development and severity of hyperglycemia in critically ill children. J Pediatr 2009;155:734-739.

33. Branco RG, Tasker RC. Glycemic level in mechanically ventilated children with bronchiolitis. Pediatr Crit Care Med 2007;8:546-550.

34. Yung M, Wilkins B, Norton L, Slater A; Paediatric Study Group; Australian and New Zealand Intensive Care Society. Glucose control, organ failure, and mortality in pediatric intensive care. Pediatr Crit Care Med 2008;9:147-152.

35. Patki VK, Chougule SB. Hyperglycemia in critically ill children. Indian J Crit Care Med 2014;18:8-13.

36. MacGregor IL, Gueller R, Watts HD, Meyer JH. The effect of acute hyperglycemia on gastric emptying in man. Gastroenterology 1976;70:190-196.

37. Schvarcz E, Palmér M, Aman J, Berne C. Hypoglycemia increases the gastric emptying rate in healthy subjects. Diabetes Care 1995;18:674-676.

38. Björnsson ES, Urbanavicius V, Eliasson B, Attvall S, Smith U, Abrahamsson $\mathrm{H}$. Effects of hyperglycemia on interdigestive gastrointestinal motility in humans. Scand J Gastroenterol 1994;29:1096-1104.

39. Rayner CK, Verhagen MA, Hebbard GS, DiMatteo AC, Doran SM, Horowitz M. Proximal gastric compliance and perception of distension in type 1 diabetes mellitus: effects of hyperglycemia. Am J Gastroenterol 2000;95:1175-1183.

40. de Boer SY, Masclee AA, lam WF, Schipper J, Jansen JB, Lamers CB. Hyperglycemia modulates gallbladder motility and small intestinal transit time in man. Dig Dis Sci 1993;38:2228-2235.

41. Lingenfelser T, Sun W, Hebbard GS, Dent J, Horowitz M. Effects of duodenal distension on antropyloroduodenal pressures and perception are modified by hyperglycemia. Am J Physiol 1999;276:G711-718.

42. Barnett JL, Owyang C. Serum glucose concentration as a modulator of interdigestive gastric motility. Gastroenterology 1988;94:739-744. Erratum in: Gastroenterology 1988;95:262.

43. Schvarcz E, Palmér M, Aman J, Horowitz M, Stridsberg M, Berne C. Physiological hyperglycemia slows gastric emptying in normal subjects and patients with insulin-dependent diabetes mellitus. Gastroenterology 1997;113:60-66.

44. Rayner CK, Park HS, Doran SM, Chapman IM, Horowitz M. Effects of cholecystokinin on appetite and pyloric motility during physiological hyperglycemia. Am J Physiol Gastrointest Liver Physiol 2000;278:G98-G104.
45. Petrakis IE, Vrachassotakis N, Sciacca V, Vassilakis SI, Chalkiadakis G. Hyperglycaemia attenuates erythromycin-induced acceleration of solid-phase gastric emptying in idiopathic and diabetic gastroparesis. Scand J Gastroenterol 1999;34:396-403.

46. Corrall RJ, Frier BM, Davidson NM, Hopkins WM, French EB. Cholinergic manifestations of the acute autonomic reaction to hypoglycaemia in man. Clin Sci (Lond) 1983;64:49-53.

47. Hilsted J, Bonde-Petersen F, Nørgaard MB, et al. Haemodynamic changes in insulin-induced hypoglycaemia in normal man. Diabetologia 1984;26:328-332.

48. Yuan CS, Foss JF, O'Connor M, Roizen MF, Moss J. Effects of lowdose morphine on gastric emptying in healthy volunteers. J Clin Pharmacol 1998;38:1017-1020.

49. Crighton IM, Martin PH, Hobbs GJ, Cobby TF, Fletcher AJ, Stewart PD. A comparison of the effects of intravenous tramadol, codeine, and morphine on gastric emptying in human volunteers. Anesth Analg 1998;87:445-449.

50. Mittal RK, Frank EB, Lange RC, McCallum RW. Effects of morphine and naloxone on esophageal motility and gastric emptying in man. Dig Dis Sci 1986;31:936-942.

51. Yuan CS, Foss JF. Gastric effects of methylnaltrexone on mu, kappa, and delta opioid agonists induced brainstem unitary responses. Neuropharmacology 1999;38:425-432.

52. Taguchi A, Sharma N, Saleem RM, et al. Selective postoperative inhibition of gastrointestinal opioid receptors. N Engl J Med 2001;345:935-940.

53. Schang JC, Hémond M, Hébert M, Pilote M. How does morphine work on colonic motility? An electromyographic study in the human left and sigmoid colon. Life Sci 1986;38:671-676.

54. Frantzides CT, Cowles V, Salaymeh B, Tekin E, Condon RE. Morphine effects on human colonic myoelectric activity in the postoperative period. Am J Surg 1992;163:144-148; discussion 148-149.

55. Edin R, Lundberg J, Terenius L, et al. Evidence for vagal enkephalinergic neural control of the feline pylorus and stomach. Gastroenterology 1980;78:492-497.

56. Walldén J, Thörn SE, Lövqvist A, Wattwil L, Wattwil M. The effect of anesthetic technique on early postoperative gastric emptying: comparison of propofol-remifentanil and opioid-free sevoflurane anesthesia. J Anesth 2006;20:261-267.

57. Fruhwald S, Herk E, Petnehazy T, et al. Sufentanil potentiates the inhibitory effect of epinephrine on intestinal motility. Intensive Care Med 2002;28:74-80.

58. Lee TL, Ang SB, Dambisya YM, Adaikan GP, Lau LC. The effect of propofol on human gastric and colonic muscle contractions. Anesth Analg 1999;89:1246-1249.

59. Jensen AG, Kalman SH, Nyström PO, Eintrei C. Anaesthetic technique does not influence postoperative bowel function: a comparison of propofol, nitrous oxide and isoflurane. Can J Anaesth 1992;39:938943.

60. Hammas B, Hvarfner A, Thörn SE, Wattwil M. Propofol sedation and gastric emptying in volunteers. Acta Anaesthesiol Scand 1998;42:102-105. 
61. Chassard D, Lansiaux S, Duflo F, et al. Effects of subhypnotic doses of propofol on gastric emptying in volunteers. Anesthesiology 2002;97:96-101.

62. Nguyen NQ, Chapman MJ, Fraser RJ, et al. The effects of sedation on gastric emptying and intra-gastric meal distribution in critical illness. Intensive Care Med 2008;34:454-460.

63. Inada T, Asai T, Yamada M, Shingu K. Propofol and midazolam inhibit gastric emptying and gastrointestinal transit in mice. Anesth Analg 2004;99:1102-1106.

64. McArthur CJ, Gin T, McLaren IM, Critchley JA, Oh TE. Gastric emptying following brain injury: effects of choice of sedation and intracranial pressure. Intensive Care Med 1995;21:573-576.

65. Mentec H, Dupont H, Bocchetti M, Cani P, Ponche F, Bleichner G. Upper digestive intolerance during enteral nutrition in critically ill patients: frequency, risk factors, and complications. Crit Care Med 2001;29:1955-1961.

66. Helmer KS, Cui Y, Chang L, Dewan A, Mercer DW. Effects of ketamine/ xylazine on expression of tumor necrosis factor-alpha, inducible nitric oxide synthase, and cyclo-oxygenase-2 in rat gastric mucosa during endotoxemia. Shock 2003;20:63-69.

67. Sun J, Wang XD, Liu H, Xu JG. Ketamine suppresses intestinal NFkappa $\mathrm{B}$ activation and proinflammatory cytokine in endotoxic rats. World J Gastroenterol 2004;10:1028-1031.

68. Suliburk JW, Mercer DW. Ketamine attenuates early lipopolysaccharide-induced gastric dysfunction: role of stressinducible phosphoproteins. J Trauma Inj 2007;62:316-319.

69. Hoder EL, Leckman JF, Ehrenkranz R, Kleber H, Cohen DJ, Poulsen JA. Clonidine in neonatal narcotic-abstinence syndrome. N Engl J Med 1981;305:1284.

70. Finkel JC, Johnson YJ, Quezado ZM. The use of dexmedetomidine to facilitate acute discontinuation of opioids after cardiac transplantation in children. Crit Care Med 2005;33:2110-2112.

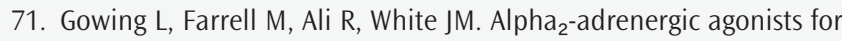
the management of opioid withdrawal. Cochrane Database Syst Rev 2016;2016:CD002024.

72. Cheng HC, Gleason EM, Nathan BA, Lachmann PJ, Woodward JK Effects of clonidine on gastric acid secretion in the rat. J Pharmacol Exp Ther 1981;217:121-126.

73. Asai T, Mapleson WW, Power I. Differential effects of clonidine and dexmedetomidine on gastric emptying and gastrointestinal transit in the rat. Br J Anaesth 1997;78:301-307.

74. Herbert MK, Roth-Goldbrunner S, Holzer P, Roewer N. Clonidine and dexmedetomidine potently inhibit peristalsis in the Guinea pig ileum in vitro. Anesthesiology 2002;97:1491-1499.

75. James AN, Ryan JP, Parkman HP. Effects of clonidine and tricyclic antidepressants on gastric smooth muscle contractility. Neurogastroenterol Motil 2004;16:143-153.

76. lirola T, Vilo S, Aantaa R, et al. Dexmedetomidine inhibits gastric emptying and oro-caecal transit in healthy volunteers. $\mathrm{Br}$ J Anaesth 2011;106:522-527.
77. Clark RA, Holdsworth CD, Rees MR, Howlett PJ. The effect on paracetamol absorption of stimulation and blockade of betaadrenoceptors. Br J Clin Pharmacol 1980;10:555-559.

78. Stieger DS, Cantieni R, Frutiger A. Acute colonic pseudoobstruction (Ogilvie's syndrome) in two patients receiving high dose clonidine for delirium tremens. Intensive Care Med 1997;23:780-782.

79. Fruhwald S, Scheidl S, Toller W, et al. Low potential of dobutamine and dopexamine to block intestinal peristalsis as compared with other catecholamines. Crit Care Med 2000;28:2893-2897.

80. Shujaa N, Al-Khrasani M, Zádori ZS, et al. $\alpha(2)$-adrenoceptor agonistinduced inhibition of gastric motor activity is mediated by $\alpha(2 \mathrm{~A})$ adrenoceptor subtype in the mouse. Neurochem Int 2011;58:708713

81. Marcoli M, Lecchini S, De Ponti F, D’Angelo L, Crema A, Frigo GM. Subsensitivity of enteric cholinergic neurones to alpha 2-adrenoceptor agonists after chronic sympathetic denervation. Naunyn Schmiedebergs Arch Pharmacol 1985;329:271-277.

82. Cohen ML, Granneman JG, Chaudhry A, Schenck KW, Cushing DJ, Palkowitz AD. Is the "atypical" beta-receptor in the rat stomach fundus the rat beta 3 receptor? J Pharmacol Exp Ther 1995;272:446451.

83. Wikberg J. Localization of adrenergic receptors in guinea pig ileum and rabbit jejunum to cholinergic neurons and to smooth muscle cells. Acta Physiol Scand 1977;99:190-207.

84. Takahashi T, Kurosawa S, Wiley JW, Owyang C. Mechanism for the gastrokinetic action of domperidone. In vitro studies in guinea pigs. Gastroenterology 1991;101:703-710.

85. Van Nueten JM, Schuurkes JA. Studies on the role of dopamine and dopamine blockers in gastroduodenal motility. Scand J Gastroenterol Suppl 1984;96:89-99.

86. Dive A, Foret F, Jamart J, Bulpa P, Installé E. Effect of dopamine on gastrointestinal motility during critical illness. Intensive Care Med 2000;26:901-907

87. Levein NG, Thörn SE, Wattwil M. Dopamine delays gastric emptying and prolongs orocaecal transit time in volunteers. Eur J Anaesthesiol 1999;16:246-250.

88. Hartley MN, Sarginson RF, Green CJ, et al. Gastric pressure response to low dose dopamine infusion in normal man. Clin Nutr 1992;11:23 29.

89. Xu X, Brining DL, Chen JD. Effects of vasopressin and long pulselow frequency gastric electrical stimulation on gastric emptying, gastric and intestinal myoelectrical activity and symptoms in dogs. Neurogastroenterol Motil 2005;17:236-244.

90. Langhans W, Delprete E, Scharrer E. Mechanisms of vasopressin's anorectic effect. Physiol Behav 1991;49:169-176.

91. Lisbon A. Dopexamine, dobutamine, and dopamine increase splanchnic blood flow: what is the evidence? Chest 2003;123(Suppl 5):460S-463S.

92. Caras SD, Soykan I, Beverly V, Lin Z, McCallum RW. The effect of intravenous vasopressin on gastric myoelectrical activity in human subjects. Neurogastroenterol Motil 1997;9:151-156. 